\title{
Clinical Improvement of Active Tuberculosis Patients with Complex Treatment and Nutritional Supplementation
}

\author{
L.V. Turchenko ${ }^{1}$, E.O. Voloshchuk ${ }^{1}$, V. Ivanov ${ }^{2}$, T. Kalinovsky ${ }^{2}$, A. Niedzwiecki*,2 and M. Rath ${ }^{2}$ \\ ${ }^{1}$ Ukraine Central TB Dispensary, Vasylkyvska str. 35, 253022, Kiev, Ukraine \\ ${ }^{2}$ Dr. Rath Research Institute, 1260 Memorex Drive, Santa Clara, CA 95050, USA
}

\begin{abstract}
Global incidence of tuberculosis, especially multiple-drug resistant tuberculosis, has been increasing, despite development and use of various antimicrobial drugs for decades, leading to 2 million deaths a year. We evaluated the effect of micronutrient supplementation as an adjunct to standard treatment of patients with active pulmonary tuberculosis, on clinical improvement and frequency of adverse events on 120 patients aged 20 to 65 years diagnosed with active pulmonary tuberculosis at the Kiev Department of Phthisiatry. All participants (Test group) were prescribed standard medication supplemented with vitamin/essential nutrients. A Control group $(n=100)$ of patients recently treated with standard medication alone at this facility were selected by matching to Test patients by stage of disease, confounding conditions, gender, and alcohol consumption. Standard clinical and diagnostic methods were applied to determine baseline values and at the termination of the study. After a two-month period of intensive chemotherapy, cavity healing (primary measure) occurred in $98 \%$ of the Test Group, but only in $69 \%$ of the Control Group. Furthermore, the Ziehl-Neelson sputum test was negative in $100 \%$ of the Test group, but only in $88 \%$ of the Control group. Resolution of respiratory compromise was higher in the Test group (87\%) than in the Control group (78\%). Furthermore, supplementation with vitamin/essential nutrients resulted in a significant decrease in the frequency and severity of adverse events from chemotherapy; only $11 \%$ in the Test group experienced adverse events while $46 \%$ did so in the Control group. In conclusion, clinical efficacy of chemotherapy was enhanced significantly with adjunctive use of nutrient supplementation. In addition, micronutrient supplementation decreased the frequency and severity of adverse effects from chemotherapy.
\end{abstract}

Keywords: Active tuberculosis, clinical, cavity healing, negative sputum smear, nutrient supplementation.

\section{INTRODUCTION}

Mycobacterium tuberculosis (M. tuberculosis) is one of the most ubiquitous pathogens in the world with roughly one third of the world's population infected with the bacillus. Tuberculosis (TB) remains one of the world's leading infectious causes of death among adults. The global incidence of tuberculosis, 8-12 million new cases of active tuberculosis a year, resulting in deaths of over two million people a year, has been increasing by $1 \%$ annually since 1980 . Developing countries have $90 \%$ of the world's TB cases, with incidence concentrated mainly in Africa, secondary to TB infection in HIV-infected persons, and in Eastern Europe and Russia, due to the emergence of multidrug-resistant TB (MDR-TB) [1, 2].

Ukraine's estimated tuberculosis case rate of 95 cases per year per 100,000 people is the eighth highest in Europe and Eurasia. According to the World Health Organization's Global Tuberculosis Control: WHO Report 2004, Ukraine had nearly $47,000 \mathrm{~TB}$ cases in 2002. Of these about half of the cases were sputum smear-positive TB, a rate of 43 cases per 100,000 people. An estimated $6 \%$ of TB cases are HIVpositive and $12-15 \%$ of new TB patients have MDR-TB [3]. Tuberculosis patients from the Ukraine, parts of the Baltic States, Russian Federation, and Central Asia, are ten times

*Address correspondence to this author at the 1260 Memorex Drive, Santa Clara, CA 95050, USA; Tel: 408-807-5564; Fax: 408-567-5030;

E-mail: author@drrath.com more likely to have MDR-TB (a strain of TB that is resistant to the bactericidal effects of isoniazid and rifampin) than the rest of the world. Treatment for MDR-TB, which often requires up to two years of daily use of multiple TB drugs with serious adverse effects, results in death of $40-60 \%$ of patients treated [4]. The increasing incidence of tuberculosis worldwide, especially MDR-TB necessitates a new more effective less toxic treatment alternative. Hepatotoxicity is the most common adverse effect of standard TB treatment, which varies from a rise in transaminases (which in extreme cases may lead to interruption of TB treatment) to acute liver failure and even death. Hepatotoxicity due to isoniazid is most common, especially when combined with rifampin; however, pyrazinamide is the most hepatotoxic among essential antiTB drugs [5, 6].

Epidemiological evidence indicates that tuberculosis is a disease associated with malnutrition. Malnutrition and clinical deficiency of specific nutrients essential for immune system function leads to immune deficiency and higher susceptibility to bacterial, viral and other infections. Immune enhancing nutrients such as vitamin $\mathrm{C}$ and other antioxidants have shown beneficial effects in various types of infections, including TB. Antioxidants used in conjunction with standard TB regimens, have been shown to accelerate healing from tuberculosis [7]. Early in vitro studies by Bossevain and Spillane showed that an ascorbate concentration of 1 $\mathrm{mg} / \mathrm{dl}$, which is easily reached in the blood, prevents the growth of cultures of M. tuberculosis [8]. Nutrients such as 
vitamin $\mathrm{C}$ and lysine can help improve immune system function, but also contribute to halting the spread of infectious agents. According to Rath and Pauling [9] these nutrients are critical for inhibiting the activity of plasmin and matrix metalloproteinases (MMP-2 and MMP-9) and for maintaining optimum synthesis and structure of the connective tissue. The effectiveness of this approach through the defined nutrient synergy has been confirmed in cancer, where similarly to infections, the enzymatic destruction of the connective tissue is involved $[10,11]$.

As a matter of fact, tuberculosis patients are found to have elevated MMP-9 levels [12-14], which is correlated with severity of illness in patients with active tuberculosis [13]. MMP-9 is secreted by both the bacillus and host response to infection with M. tuberculosis. MMP-9 activity was specifically increased in patients with neurological complications [12]. Our previous studies have demonstrated that adequate levels of ascorbic acid, proline and lysine can prevent MMP-9 secretion and degradation of collagen matrix in various systems $[10,11]$.

Pulmonary TB involves many other pathomechanisms, such as inflammation-related oxidative stress, which has been implicated in development of lung fibrosis and dysfunction in patients with pulmonary TB. TB patients, even after six months of apparently successful drug treatment, still demonstrated high levels of circulating lipid peroxides and low concentrations of plasma vitamin E [15]. Administration of nutrients such as ascorbic acid and alpha tocopherol have been shown to accelerate tuberculosis healing, based on decay cavity closure and negative sputum [16]. Furthermore, a clinical trial cohort study of 26,975 Finnish men during a median follow-up of 6.7 years found a high inverse association between calculated vitamin $\mathrm{C}$ intake and incidence of tuberculosis. Subjects with intake of $>90 \mathrm{mg}$ of vitamin C and with increased consumption of fruits, vegetable and berries had significantly lower risk of tuberculosis [17].

The rationale for a multi-nutrient approach in TB is based on complex biochemical processes simultaneously involved in this disease that can only be effectively addressed using an essential synergistically acting nutrient combination, in contrast to using a single nutrient or a randomly selected mixture.

\section{Objectives}

The objective of this clinical study was to investigate whether a combination of vitamins, amino acids, and other essential nutrients as an adjunct to standard treatment of patients with active pulmonary tuberculosis could lead to increased clinical improvement and reduction of adverse events associated with standard tuberculosis pharmaceutical treatment.

\section{STUDY POPULATION AND METHODS}

\section{Participants}

An open label study conducted February 2004 to December 2005 at the Kiev Department of Phthisiatry was undertaken on 120 hospitalized patients (Test group), aged 20 to 65 years, male and female, diagnosed with active pulmonary tuberculosis, receiving standard tuberculosis pharmaceutical treatment $\left(1^{\text {st }}\right.$ or $3^{\text {rd }}$ category treatment, depending upon severity and distribution pattern of the pathological processes).
(See Appendix -STARD diagram) Inclusion criteria for selection were: males/females from 18 to 65 years of age diagnosed with active pulmonary tuberculosis. An historical Control group of 100 patients matched to the Test group in regards to the stage of disease, confounding conditions, gender, and alcohol consumption was selected from the same facility. (See Table 1 for baseline demographics and characteristics and for confounding conditions.) Symptom evaluation, diagnosis and treatment assignments were done in strict accordance with the Ukrainian Ministry of Health guidelines (publication \#26 from 01/23/2003 "On prevention and treatment of tuberculosis") and by the Department of Health, City of Kiev, (publication \#185 from 04/04/2003 "On prevention and treatment of tuberculosis in the city of Kiev").

Table 1. Participant Clinical Parameters

\begin{tabular}{|c|c|c|}
\hline Patient parameters & $\begin{array}{l}\text { Test Group } \\
\mathrm{n}=120\end{array}$ & $\begin{array}{l}\text { Control Group } \\
\mathbf{n}=\mathbf{1 0 0}\end{array}$ \\
\hline $\begin{array}{l}\text { Gender: } \\
\text { Male } \\
\text { Female }\end{array}$ & $\begin{array}{l}44(37 \%) \\
76(63 \%)\end{array}$ & $\begin{array}{l}28(28 \%) \\
72(72 \%)\end{array}$ \\
\hline $\begin{array}{l}\text { Age: } \\
20-29 \\
30-39 \\
40-49 \\
50-59 \\
60+\end{array}$ & $\begin{array}{l}10(8 \%) \\
14(12 \%) \\
54(45 \%) \\
37(31 \%) \\
5(4 \%)\end{array}$ & $\begin{array}{l}4(4 \%) \\
6(6 \%) \\
52(52 \%) \\
33(33 \%) \\
5(5 \%)\end{array}$ \\
\hline $\begin{array}{l}\text { Clinical Forms of TB: } \\
\text { Localized } \\
\text { Infiltrated } \\
\text { Disseminated }\end{array}$ & $\begin{array}{l}42(35 \%) \\
69(58 \%) \\
9(7 \%)\end{array}$ & $\begin{array}{l}32(32 \%) \\
59(59 \%) \\
9(9 \%)\end{array}$ \\
\hline $\begin{array}{l}\text { Lung Failure: } \\
\text { Light (1st degree) } \\
\text { Moderate (2nd degree) } \\
\text { Advanced }\left(3^{\text {rd }} \text { degree }\right) \\
\text { Absent }\end{array}$ & $\begin{array}{l}66(55 \%) \\
16(13 \%) \\
0 \\
38(32 \%)\end{array}$ & $\begin{array}{l}56(56 \%) \\
5(5 \%) \\
0 \\
39(39 \%)\end{array}$ \\
\hline $\begin{array}{l}\text { Bronchial Inflammation: } \\
\text { 1st degree } \\
\text { 2nd degree } \\
\text { Absent }\end{array}$ & $\begin{array}{l}48(40 \%) \\
3(3 \%) \\
69(57 \%)\end{array}$ & $\begin{array}{l}41(41 \%) \\
2(2 \%) \\
57(57 \%)\end{array}$ \\
\hline Smokers & $69(58 \%)$ & $58(58 \%)$ \\
\hline Alcohol consumers & $15(13 \%)$ & $21(21 \%)$ \\
\hline $\begin{array}{l}\text { Confounding conditions } \\
\text { Chronic bronchitis }\end{array}$ & $64(53 \% 0$ & $48(48 \%)$ \\
\hline Ischemic heart disease & $18(15 \%)$ & $20(20 \%)$ \\
\hline Hypertension & $9(8 \%)$ & $3(3 \%)$ \\
\hline Neuro-circulative dystonia & $7(6 \%)$ & $2(2 \%)$ \\
\hline Ulcer of stomach or duodenum & $6(5 \%)$ & $9(9 \%)$ \\
\hline Diabetes mellitus & $3(2.5 \%)$ & $2(2 \%)$ \\
\hline Autoimmune thyroid disease & $2(2 \%)$ & $0(0 \%)$ \\
\hline Toxic thyroid disease & $2(2 \%)$ & $1(1 \%)$ \\
\hline Chronic hepatitis & $2(2 \%)$ & $0(0 \%)$ \\
\hline Chronic pyelonephritis & $3(2.5 \%)$ & $3(3 \%)$ \\
\hline
\end{tabular}




\section{Interventions}

The Control group of patients was treated with conventional tuberculosis medications, as indicated below. The Test group was supplied with vitamin/essential nutrient supplementation adjunctively with conventional medications. Complete composition of the vitamin/essential nutrient supplement is listed in Table 2 . Tuberculosis therapy consisted of $1^{\text {st }}$ or $3^{\text {rd }}$ category treatment, depending on the severity and distribution pattern of the pathological processes (Table 3 ). Patients allocated to the $1^{\text {st }}$ treatment category were diagnosed with widespread pathological processes (more than two lung segments) or presence of regions with decay. Category 1 treatment consisted of the following regimens: A:

Table 2. Composition of Nutritional Supplement (Serving Size-One Tablet Per Day)

\begin{tabular}{|l|l|}
\hline Vitamin A (from 7.5\% Betatene (Henkel)) & $528 \mathrm{IU}$ \\
\hline $\begin{array}{l}\text { Vitamin C as Ascorbic Acid, Ascorbyl Palmitate, } \\
\text { Calcium Ascorbate, Magnesium Ascorbate }\end{array}$ & $200 \mathrm{mg}$ \\
\hline Vitamin D3 (as Cholecalciferol) & $43.3 \mathrm{IU}$ \\
\hline Vitamin E (Mixed Covitol) & $43.3 \mathrm{IU}$ \\
\hline Vitamin B1 (from Thiamine Mononitrate & $2.3 \mathrm{mg}$ \\
\hline Vitamin B2 (as Riboflavin) & $2.3 \mathrm{mg}$ \\
\hline Niacin (as from Niacinamide) & $15 \mathrm{mg}$ \\
\hline Vitamin B6 (from Pyridoxine HCl) & $3.3 \mu \mathrm{g}$ \\
\hline Folic Acid & $10 \mu \mathrm{g}$ \\
\hline Vitamin B12 (as Cyanocobalamin) & $6.7 \mu \mathrm{g}$ \\
\hline Biotin & $21.7 \mu \mathrm{g}$ \\
\hline Pantothenic Acid (from D-Calcium Pantothenate) & $13.3 \mu \mathrm{g}$ \\
\hline Calcium (from Glycinate, Ascorbate) & $11.7 \mathrm{mg}$ \\
\hline Phosphorus (from Dicalcium Phosphate) & $5 \mathrm{mg}$ \\
\hline $\begin{array}{l}\text { Magnesium (from Magnesium Glycinate, Magnesium } \\
\text { Ascorbate) }\end{array}$ & $13.3 \mathrm{mg}$ \\
\hline Zinc (from Zinc Glycinate) & $2.3 \mathrm{mg}$ \\
\hline Selenium (from L-Selenomethionine) & $6.7 \mu \mathrm{g}$ \\
\hline Copper (from Copper Glycinate) & $110 \mu \mathrm{g}$ \\
\hline Manganese (from Amino Acid Chelate) & $.33 \mathrm{mg}$ \\
\hline Chromium (from Chromium Glycinate) & $3.3 \mu \mathrm{g}$ \\
\hline Molybdenum (from Molybdenum Glycinate) & $1.3 \mu \mathrm{g}$ \\
\hline Potassium (from Potassium Proteinate) & $6.7 \mathrm{mg}$ \\
\hline L-Lysine (from L-Lysine HCl) & $36.7 \mathrm{mg}$ \\
\hline L-Proline & $36.7 \mathrm{mg}$ \\
\hline Citrus Fruit Peel Bioflavanoids & $33.3 \mathrm{mg}$ \\
\hline L-Arginine (from L-Arginine HCl) & $13.3 \mathrm{mg}$ \\
\hline L-Cysteine (from L-Cysteine Monohydrate HCl) & $11.7 \mathrm{mg}$ \\
\hline Inositol & $\mathrm{mg}$ \\
\hline L-Carnitine (from L-Carnitine Tartrate & $2.3 \mathrm{mg}$ \\
\hline CoEnzyme Q10 & \\
\hline Pycnogenol & \\
\hline
\end{tabular}

isoniazid + rifampin + pyrazinamide + ethambutol or B: isoniazid + rifampin + pyrazinamide + streptomycin. Patients allocated to Category 3 treatment demonstrated limited pathological processes (no more than two lung segments), without decays and with negative mucosa swipe test. Category 3 treatment consisted of the following regimen: isoniazid + rifampin + pyrazinamide. All medications were prescribed in standard doses. (isoniazid $5 \mathrm{mg} / \mathrm{kg}$, rifampin 10 $\mathrm{mg} / \mathrm{kg}$, pyrazinamide $25 \mathrm{mg} / \mathrm{kg}$, ethambutol $25 \mathrm{mg} / \mathrm{kg}$, streptomycin $15 \mathrm{mg} / \mathrm{kg}$ ).

In the supplemented (Test) Group, 87 patients (72.5\%) were treated with Category 1 regimens: 24 with regimen $\mathrm{B}$ and 63 with regimen $\mathrm{A}$. In the Control Group, 73 patients (73\%)were treated with Category 1 regimens: 19 with B and 54 with A. Category 3 treatment was applied to 33 patients $(27.5 \%)$ in the Test Group and $27(27 \%)$ patients in Control Group. In addition to standard pharmaceutical treatment, the Test group patients received one tablet of the vitamin/essential nutrient supplement per day. There was no statistically significant difference in clinical parameters between the Test and Control category treatment groups at the beginning of treatment.

\section{Ethical Considerations}

The study was conducted according to the recommendations of the Declaration of Helsinki as amended in South Africa and Edinburgh, Scotland (1996 and 2000 respectively), in particular sections 40 and 41 of the Tenth Amendment to the Drugs Act, the Principles of Proper Implementation of Clinical Studies and the ICH-GCP Note for Guidance. Informed consent was obtained from all patients in the study. Symptom evaluation, diagnosis and treatment assignments were done in strict accordance with the Ukrainian Ministry of Health guidelines (publication \#26 from $01 / 23 / 2003$ "On prevention and treatment of tuberculosis") and by the Department of Health, City of Kiev, (publication \#185 from 04/04/2003 "On prevention and treatment of tuberculosis in the city of Kiev").

The Department of Health and Medical Aid at the Government of Kiev and Institute of Phthisiatry and Pulmonology, named F. G. Yanovsky Ukrainian Academy of Medical Sciences, approved the clinical study.

\section{Methods of Determining Efficacy}

The primary target parameter was the percentage of patients treated that demonstrated clinical healing of pulmonary tuberculosis decays after two months of standard tuberculosis treatment with and without supplementation. Disease progression was evaluated by radiographic technique and cavity progress was evaluated by computer tomagraphy. Secondary parameters included negative sputum test and resolution of respiratory compromise. Phlegm analysis was done three times by microscopy and Ziehl-Neelsen staining of the specimens. Respiratory function was evaluated by computer-controlled "Pulmovent-2" (Sensor Systems, Kiev, Ukraine). The tertiary parameter was the frequency and severity of chemotherapy-related adverse events experienced in the Test (vitamin/essential nutrient supplemented) group contrasted to the Control group. Staff physicians were responsible with monitoring of treatment, adjustment of prescribed treatment, when necessary, and recording of clinical 
Table 3. Treatment Categories

\begin{tabular}{|c|c|c|}
\hline Treatment Category & $\begin{array}{l}\text { Test Group }(\mathrm{n}=120) \\
\text { \# (\%) of Patients }\end{array}$ & $\begin{array}{l}\text { Control Group }(n=100) \\
\text { \# (\%) of Patients }\end{array}$ \\
\hline \multicolumn{3}{|c|}{ Category 1 - widespread pathological processes (more than two lung segments) or presence of regions with decay } \\
\hline $\begin{array}{l}\text { Category } 1 \mathrm{~A} \\
\text { isoniazid }+ \text { rifampicin }+ \text { pyrazinamide }+ \text { ethambutol }\end{array}$ & $63(52.5 \%)$ & $54(54 \%)$ \\
\hline \multicolumn{3}{|c|}{ Category 3 - limited pathological processes (no more than two lung segments), without decays and with negative mucosa swipe test } \\
\hline $\begin{array}{l}\text { Category } 3 \\
\text { isoniazid }+ \text { rifampicin }+ \text { pyrazinamide }\end{array}$ & $33(27.5 \%)$ & $27(27 \%)$ \\
\hline
\end{tabular}

progress. Specialists provided radiographic diagnostics, bacteriological analysis, and respiratory functional diagnostics (such as CT). The principle investigator managed medication distribution, control of treatment compliance and collection of specimens (blood, urine, and phlegm) for analysis.

\section{Statistical Methods}

For confirmatory analysis of the main target parameter, the Mantel-Haenszel chi-square test was used.

\section{RESULTS}

All patients in the study completed the 2-month inhospital treatment program with complete compliance. All historical Control group patients had completed the same standard protocol but without nutrient supplementation.

\section{Effect of Vitamin/Essential Nutrient Supplementation on Clinical Healing}

For the primary efficacy parameter (percent of patients in each group reaching clinical healing of tuberculosis after two months treatment based on cavity healing), vitamin/essential nutrient supplementation significantly increased the number of patients experiencing healing of decays (See Table 4). Healing of cavities was significantly higher (by $29.4 \%$, $\mathrm{p}<0.0001$ ) in the Test Group than in the Control Group. The presence of cavities was observed in 2 patients in the Test Group and in 31 patients in Control Group.

Furthermore, after a two-month period of intensive therapy, the Ziehl-Neelson sputum test was negative in all patients from the Test Group (100\%), but only in $88 \%$ of the patients in the Control Group (Table 4). Supplementation decreased the percentage of patients demonstrating a positive live bacteria sputum test by $12 \% \quad(p<0.0003)$. Vita$\mathrm{min} /$ essential nutrient supplementation also had a significant effect on obstructive respiratory compromise. After twomonth treatment only 15 Test patients (13\%) still demonstrated mild respiratory compromise. In contrast, in the Control group, after the two-month treatment, 22 patients $(22 \%)$ still experienced respiratory compromise, including two moderate cases (Table 4). The results demonstrated significant increased clinical healing with vitamin/essential nutrient supplementation to standard anti-tuberculosis therapy. Other clinical measures, such as liver enlargement, productive coughing, rales, bronchial catarrhal changes, and accelerated
RBC sedimentation (sed) rate were significantly reduced in supplemented patients, as shown in Table 4.

\section{Effect of Vitamin/Essential Nutrient Supplementation on Adverse Effects from Conventional Therapy}

Analysis of data demonstrated a significant decrease in the frequency $(35 \%$ decrease, $\mathrm{p}<0.0001)$ and severity of adverse events from standard drug therapy in the vitamin/essential nutrient supplemented group (Test) group in contrast to the Control group (Table 5). In the group taking the vitamin/essential nutrient supplement (Test), $107(90 \%)$ patients experienced good tolerance to their standard therapy and $13(11 \%)$ patients reported short-term mild adverse events that did not require any corrective treatment. In the Control group, adverse events to standard drug regimens were significantly more frequent, affecting 46\% (46/100) of the patients, some requiring corrective treatment. In both groups, the adverse events usually appeared during the first and second week of chemotherapy.

\section{DISCUSSION}

Treatment with a multivitamin/essential nutrient combination in conjunction with standard drug regimens over a two-month period significantly accelerated clinical healing of tuberculosis than did the standard drug regimens alone. Furthermore, healing of tuberculosis was accompanied by significantly reduced frequency and severity of adverse events from standard chemotherapy. These effects were achieved by addressing underlying cellular mechanisms involved in tuberculosis, which relate to deficiency or imbalances of essential nutrients, especially antioxidants.

It is well known that tuberculosis is a disease of immune deficiency, arising from malnutrition. Epidemiological data demonstrates that tuberculosis is most prevalent in poverty areas; $95 \%$ of those ill with TB and $98 \%$ of those who die of $\mathrm{TB}$, live in the developing world [2]. The vast majority of those infected with the bacillus will never develop any clinical illness. Some will develop active disease due to some impairment of their immune system, secondary to HIV infection, malnutrition or advanced malignancy [18]. In addition, there is compelling clinical evidence that in addition to the innate virulence of the tubercle bacillus itself, host response plays a major role in determining the clinical manifestations and ultimate outcome of persons infected by this pathogen. 
Table 4. Clinical Efficacy of Chemotherapy with and without Supplementation

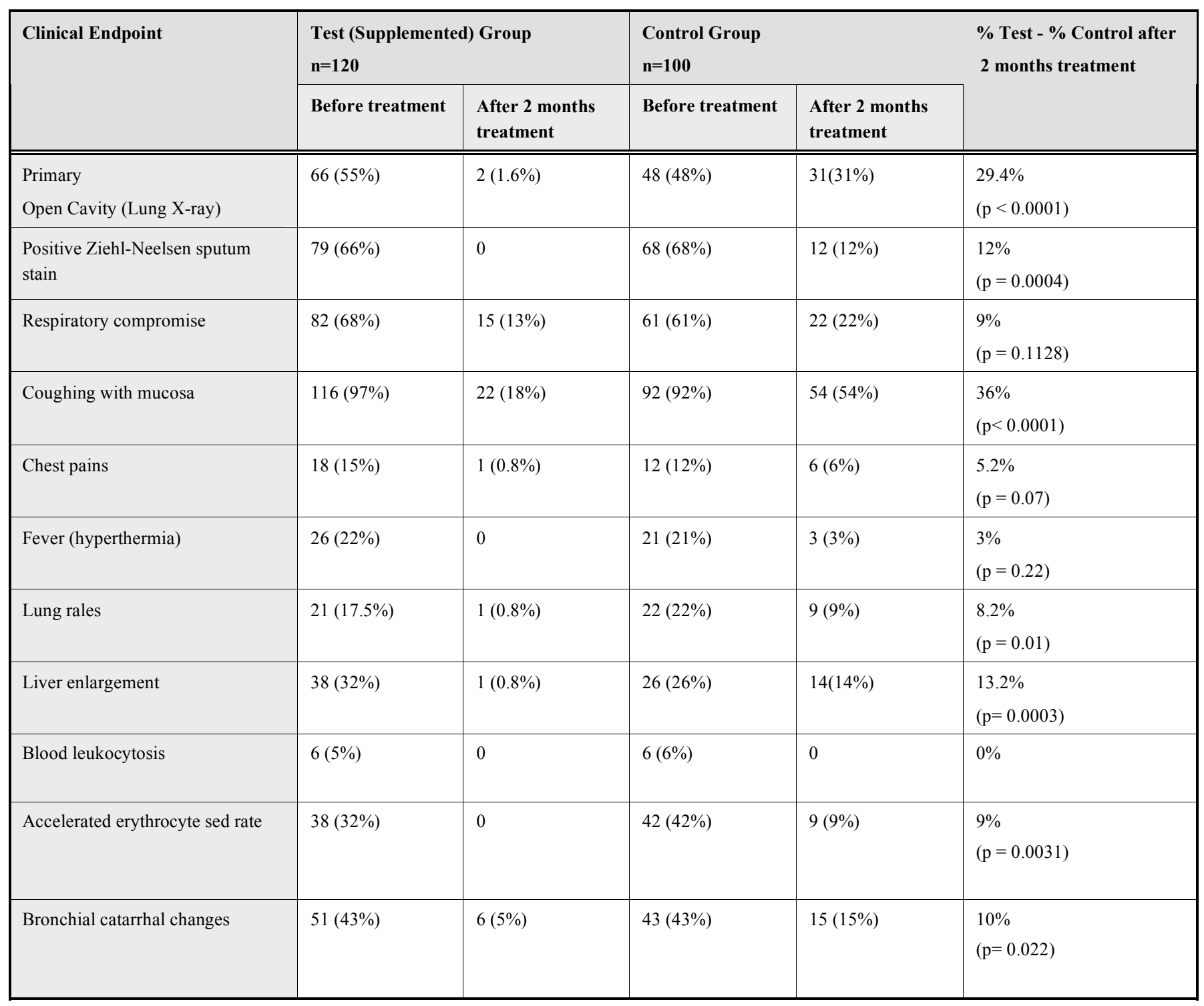

Comparison of the $\%$ of patients from the total number in each group experiencing the listed parameters after two months treatment

Table 5. Frequencies and Types of Adverse Events from Chemotherapy with or without Vitamin/Essential Nutrient Supplementation

\begin{tabular}{|l|l|l|}
\hline Adverse events & Treatment Group (n=120) & Control Group (n=100) \\
\hline \hline $\begin{array}{l}\text { Allergic reactions } \\
\text { Dermatitis, pruritis }\end{array}$ & $1(0.8 \%)$ & $18(18 \%)$ \\
Hyperthermia & & $1(1 \%)$ \\
\hline $\begin{array}{l}\text { Toxic reactions } \\
\text { Dyspepsia, nausea } \\
\text { Intestinal }\end{array}$ & $12(10 \%)$ & $19(19 \%)$ \\
\hline $\begin{array}{l}\text { Toxic-allergic reactions } \\
\text { Hyperthermia }\end{array}$ & 0 & $3(22 \%)$ \\
Angioedema & & $4(4 \%)$ \\
\hline No adverse events & $107(89 \%)$ & $1(1 \%)$ \\
\hline
\end{tabular}


These findings are supported by clinical research on antioxidant levels in patients diagnosed with tuberculosis. Patients infected with tuberculosis have decreased antioxidant levels (vitamins C, E and A) [19] and increased lipid peroxidation [20]. In studying plasma levels of antioxidants in 41 patients with active tuberculosis at onset and after six months of drug therapy, Plit et al. [15] found increased levels of circulating lipid peroxides and low concentrations of plasma vitamin E. Bakaev et al. [21] measured the levels of ascorbic, dehydroascorbic and diketogulonic acids in blood serum of patients with pulmonary tuberculosis and pneumonia and found lower serum levels of ascorbic acid and dehydroascorbic acid in pulmonary TB patients. Vijayamalini and Manoharan [20] examined the relationship between lipid peroxidation and vitamin $\mathrm{C}$, vitamin $\mathrm{E}$ and reduced glutathione levels in plasma, erythrocytes and erythrocyte membranes of pulmonary tuberculosis patients compared to an equal number of age and sex matched healthy subjects. Pulmonary tuberculosis patients demonstrated increased lipid peroxidation levels and decreased vitamin $\mathrm{E}$ and $\mathrm{C}$ and reduced glutathione levels, indicating the potential of oxidative damage to erythrocytes and erythrocyte membranes [20].

Furthermore, clinical studies have demonstrated increased antioxidant levels after treatment of tuberculosis with adjunctive use of vitamin $\mathrm{C}$ and $\mathrm{E}$ with chemotherapy. In a study of 40 patients with diagnosed infiltrative pulmonary tuberculosis treated with tuberculostatic drugs and a month of adjunctive treatment with Vitamin C (1000 $\mathrm{mg}$ /day) and Vitamin E (600 mg/day) resulted in increased antioxidant activity compared to the control group [7]. In another study, administration of alpha-tocopherol, vitamin C and sodium nucleinate in conjunction with chemotherapeutic drugs brought about higher rates of smear-negative cases and shorter period of cavity closure than drugs alone [16].

The results of this study indicate that enhanced clinical healing can be achieved in TB patients using a wide spectrum of micronutrients with relatively low doses of antioxidants to enhance comprehensive physiological effects. Although the trial used a historical Control group, this group was matched to the Test group by stage of disease, confounding conditions, gender, and alcohol consumption. In addition both groups were treated using the same protocols at the same institution in a controlled inpatient setting. Although prior dietary history was not known, the diet provided during the inpatient study was uniform.

\section{CONCLUSION}

In conclusion, the vitamin essential nutritional supplement used with standard TB drug therapy demonstrated significant clinical improvement in TB patients over standard medication alone. In addition, daily supplementation with this nutrient combination significantly reduced the frequency and severity of adverse events associated with standard drug therapy. Though this clinical study did not investigate the mechanism of the nutrients on clinical healing of tuberculosis, the mechanism of action of nutrients, such as vitamin $\mathrm{C}$ are well known. For example, not only has vitamin $\mathrm{C}$ been shown to retard growth of M. tuberculosis, but has also been shown to act with lysine to inhibit MMP degradation of connective tissue. Furthermore, antioxidants have been shown to accelerate healing of TB. Based on the results of this study, large clinical trials are indicated and supplementation with vitamin/essential nutrients as an adjunct to antituberculosis treatment is advisable.

\section{REFERENCES}

[1] World Economic Forum. Global Fund Initiative: Tuberculosis http://www.theglobalfund.org/en/files/about/replenishment/disease report tb en.pdf (accessed December 1, 2005).

[2] Javid, $\overline{\mathrm{S}}$. The Body: The tuberculosis (TB) treatment pipeline. http://www.thebody.com/tag/pipeline05/tb.html (accessed December 1,2005 ).

[3] USAID Health, Infectious Diseases, Tuberculosis, Countries, Ukraine. http://www.usaid.gov/our work/global health/id/tuberculosis/countires/eande/ukraine_pro.htm (accessed December 1, 2005).

[4] National Institute of Allergy and Infectious Diseases/National Institutes of Health. http://www.niaid.nih.gov/factsheets/tb.htm (accessed December 1, 2005).

[5] Zaleskis, R. Breathe, 2005, 2(1), 69-73.

[6] Springhouse. Nursing 2000 Drug Handbook. Lippincott Williams \& Wilkins, Springhouse, Pennsylvania, 2000.

[7] Kowalski, J.; Janiszewska-Drobinska, B.; Pawlicki, L.; Ceglinski, T.; Irzmanski, R. Pol. Merkurtusx Lek., 2004, 16(92), 119-22.

[8] Bossevain, C.G.; Spillane, J.H. Am. Rev. Tuberc., 1937, 35, 661662.

[9] Rath, M.; Pauling, L. J. Ortho. Med., 1992, 7, 17-23.

[10] Roomi, M.W.; Ivanov, V.; Kalinovsky, T.; Niedzwiecki, A.; Rath, M. Int. J. Gastrointest. Cancer, 2005, 35(2), 97-102.

[11] Roomi, M.W.; Roomi, N.; Ivanov, V.; Kalinovsky, T.; Niedzwiecki, A.; Rath, M. Oncol. Rep., 2005, 14(4), 807-815.

[12] Price, N.M.; Farrar, J.; Tran, T.T.; Nguyen, T.H.; Tran, T.H.; Friedland, J.S. J. Immunol., 2001, 166, 4223-4230.

[13] Park, K.J.; Hwang, S.C.; Sheen, S.S.; Oh, Y.J.; Han, J.H.; Lee, K.B. Respiration, 2005, 72(2), 166-175

[14] Hrabec, E.; Strek, M.; Zieba, M.; Kwiatkowska, S.; Hrabec, Z. Int. J. Tuberc. Lung Dis., 2002, 6(8), 713-719.

[15] Plit, M.; Theron, A.; Fickl, H.; van Rensbury, C.; Pendel, S.; Anderson, R. Int. J. Tuberc. Lung Dis., 1998, 2(7), 590-6.

[16] Safarian, M.D.; Karagezian, K.G.; Karapetian, E.T.; Avanesian, N.A. Probl. Tuberk., 1990, 5, 40-4.

[17] Hemila, H.; Kaprio, J.; Pietinen, P.; Albanes, D.; Heinonen, O.P. Am. J. Epidemiol., 1999, 150(6), 632-41.

[18] Young, L.S. Clin. Infect. Dis., 1993, 17 (Suppl. 2), S436-S441.

[19] Madebo, T.; Lindtjorn, B.; Aukrust, P.; Berge, R.K. Am. J. Clin. Nutr., 2003, 78, 117-22.

[20] Vijayamalini, M.; Manoharan, S. Cell Biochem. Funct., 2004, 22(1), 19-22.

[21] Bakaev, V.V.; Duntau, A.P. Int. J. Tuberc. Lung Dis., 2004, 8(2), 263-6. 
Appendix 1. STARD (Standards for Reporting of Diagnostic Accuracy) Flow Diagram

220 patients presented for treatment at the Kiev Department of Phthisiatry from January 2003 December 2005 and were assessed for eligibility for 2-month TB treatment

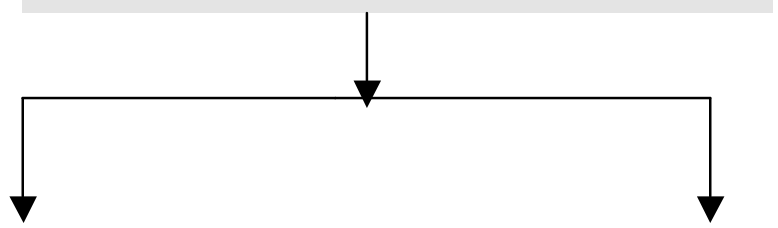

120 patients assessed for eligibility for 2month inpatient study (February 2004 to December 2005 ) were allocated to Test group (ITT analysis)

Received vitamin supplementation + conventional medication (according to severity of condition):

87 assigned to Category 1 regimens 33 assigned to Category 3 regimen

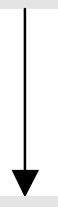

120 patients completed the 2 month in-patient program. Neither dropouts nor major protocol deviations occurred.
100 patients selected by matching patients to Test group by stage of disease, confounding conditions, gender, and alcohol consumption from previous 2-month inpatient treatment program (treated from January 2003-January 2004) were allocated to the Control group Patients had all received conventional medication (according to severity of condition):

73 assigned to Category 1

27 assigned to Category 3 regimen

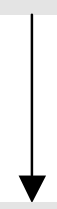

100 patients completed the 2month in-patient program. Neither dropouts nor major protocol deviations occurred. 